\title{
Potential of Carbon Nanotube Reinforced Cement Composites as Concrete Repair Material
}

\author{
Tanvir Manzur, ${ }^{1}$ Nur Yazdani, ${ }^{2}$ and Md. Abul Bashar Emon ${ }^{1}$ \\ ${ }^{1}$ Department of CE, BUET, Dhaka 1000, Bangladesh \\ ${ }^{2}$ Department of CE, University of Texas at Arlington, Arlington, TX 76019, USA \\ Correspondence should be addressed to Tanvir Manzur; tmanzur.buet@gmail.com
}

Received 16 December 2015; Revised 7 February 2016; Accepted 8 February 2016

Academic Editor: Brigitte Vigolo

Copyright (C) 2016 Tanvir Manzur et al. This is an open access article distributed under the Creative Commons Attribution License, which permits unrestricted use, distribution, and reproduction in any medium, provided the original work is properly cited.

\begin{abstract}
Carbon nanotubes (CNTs) are a virtually ideal reinforcing agent due to extremely high aspect ratios and ultra high strengths. It is evident from contemporary research that utilization of CNT in producing new cement-based composite materials has a great potential. Consequently, possible practical application of CNT reinforced cementitious composites has immense prospect in the field of applied nanotechnology within construction industry. Several repair, retrofit, and strengthening techniques are currently available to enhance the integrity and durability of concrete structures with cracks and spalling, but applicability and/or reliability is/are often limited. Therefore, there is always a need for innovative high performing concrete repair materials with good mechanical, rheological, and durability properties. Considering the mechanical properties of carbon nanotubes (CNTs) and the test results of CNT reinforced cement composites, it is apparent that such composites could be used conveniently as concrete repair material. With this end in view, the applicability of multiwalled carbon nanotube (MWNT) reinforced cement composites as concrete repair material has been evaluated in this study in terms of setting time, bleeding, and bonding strength (slant shear) tests. It has been found that MWNT reinforced cement mortar has good prospective as concrete repair material since such composites exhibited desirable behavior in setting time, bleeding, and slant shear.
\end{abstract}

\section{Introduction}

In the field of nanotechnology, carbon nanotube (CNT) has the prime focus as one of the most major and significant areas of research. There is a keen interest in developing nanotechnology for cement and concrete. Not only the chemistry of cement hydration products but also the physical behavior of these hydration products can be modified through application of nanotechnology due to their dimensional scale. The mechanical properties of CNT manifest immense potential to be used as reinforcements in composite materials. In addition to their high strength and elasticity, CNTs have extremely high aspect ratios, with values typically higher than 1000:1 and reaching as high as 2,500,000:1 [1]. CNTs' ultra high aspect ratios [2], extreme high strength [3], high modulus [4], and elasticity [5] make them an idle candidate for outstanding reinforcing material within any composite matrix. The size and aspect ratios of CNT are such that it is possible to distribute them on a much finer scale than commonly used micro reinforcing fibers [1]. Cracks can be interrupted very quickly during propagation in a properly dispersed CNT reinforced matrix. Eventually, bridge coupling effect of CNT ensures relatively lower crack widths and guarantees load-transfer across voids and cracks. Therefore, CNT reinforced composites can have higher flexural and compressive strengths as well as smaller strain and higher density. These mechanical properties of CNT reflect its prospect as reinforcement within the matrix of cementitious composites.

A number of researches have already been conducted on the application of CNT for enhancing mechanical properties of cementitious composites. It has been found that research on CNT-cement composites started in the early 1990s. Chen and Chung [6] in 1993 observed an increase of 85\%, 205\%, and $22 \%$ in flexural strength, flexural toughness, and compressive strength, respectively, with the use of short carbon fibers in the cement mortar. However, significant research outcomes have been observed in mid 2000s. Li et al. [7] in 
2004 showed that both compressive and flexural strength of the cement mortar with CNTs were higher than plain cement paste. In another study [8], the same researchers in 2005 showed that porosity of cement composite can be reduced by adding CNT. Makar et al. [1] in 2005 found that addition of SWNTs (single-walled nanotubes) can accelerate the hydration of cement at early age by providing additional spaces for hydration products to grow. This behavior of CNT is analogous to their performance as nucleating agent in different applications. For example, growth of $\mathrm{Si}_{3} \mathrm{~N}_{4}$ [9], $\mathrm{ZrO}_{2}$ [10], $\mathrm{CaCO}_{3}$ [11], and nanodiamonds [12] on MWNT, MWNT, MWNT, and SWNT, respectively, can be mentioned. Cwirzen et al. [13] in 2008 obtained 10\% higher flexural strength for MWNT reinforced composites as compared to plain cement mortar. A CNT-to-cement proportion of 0.042 (percent of cement weight) was used in that research. Agullo et al. [14] in 2009 observed an increase in early age compressive strengths by adding low concentration of MWNT within cement composite. On the other hand, 28-day compressive strength was found to be similar for both normal cement mortar and nanotube reinforced composites. In another study in 2009, Makar and Chan [15] observed that nanotubes can influence the morphology of hydration products. KonstaGdoutos et al. [16] in 2010 found that cement composites having both short and long MWNT as reinforcement showed higher flexure and modulus than those of plain cement paste. Manzur and Yazdani [17] in 2010 observed increase in compressive strength of cement mortar through addition of two different sizes of untreated commercial MWNT. Hunashyal et al. [18] in 2011 obtained higher tensile strength and better stress-strain relationship in direct tension for cement samples with CNT. Han et al. [19] in 2013 showed that addition of MWNT could decrease both water sorptivity and permeability coefficient of CNT reinforced cement-based materials. In 2014, Manzur et al. [20] found that MWNT with OD (outside diameter) $20 \mathrm{~nm}$ or less obtained higher compressive strengths as compared to larger OD-MWNT when used in mortar and the maximum compressive strength was achieved by the smallest size of MWNT considered in the study. Such behavior is due to the fact that smaller size MWNTs can be distributed on much finer scale which in turn ensures efficient filling of nanopore space within the cement matrix. Finer distribution of nanotubes also enhances the performance of nanotubes as nucleating agent during cement hydration and, hence, encourages the formation of higher stiffness C-S-H phase. Lelusz [21] in 2014 found that compressive strength of cement composites decreased with the increase in CNT dosage. This research used different dosage rates of MWNT ranging from $0.00 \%$ to $0.12 \%$ by weight of cement. A suitable mix proportion was proposed by Manzur and Yazdani [22] in another study in 2015 to produce surface treated MWNT reinforced cement composites based on flexural and compressive strengths. It is, therefore, quite evident that CNT reinforcement could result in robust and improved cementitious composites. The reasons behind higher compressive strength and lesser porosity of CNT reinforced cementitious composites have been pointed out as better hydration and filling of nanospace by nanotubes in previous studies. Better hydration is caused by the role of nanotubes as nucleating agent as already mentioned above. On the other hand, enhanced flexural and tensile behavior of cement mortar reinforced by nanotubes is mainly due to crack bridging and fiber pullout actions of nanotubes. However, performance of CNT-cement composites is observed to be quite variable. Properties of CNT reinforced cementitious composites depend on several factors and mixing procedures and have been well documented by Parveen et al. [23]. The authors of the present study have studied the effect of different important parameters on different mechanical properties of CNT-cement composites and suggested a suitable mixing technique [17] and a tentative optimum mix proportion [22]. In this paper, a possible functional application of CNTcement mortar is discussed.

A potentially useful application of CNT within construction industry is in producing nanotubes reinforced cement mortar that may be employed for concrete rehabilitation, such as surface restoration and crack repair. Several repair, retrofit, and strengthening techniques are currently available to enhance the integrity and durability of concrete structures with cracks, spalling, and so forth. Current available materials like epoxy for crack repair and cementitious grouts for spalling overlay are good solutions for concrete repair. However, epoxy repair is often not suitable for repair of concrete spalling. In case of rapid hardening cementitious grout, repair depth and volume are usually kept small due to the high cost and rapid heat generation of the rapid hardening materials. Therefore, there is always a need for innovative high performing concrete repair materials with good mechanical, rheological, and durability properties. In this regard, CNT-cement composites appear to have good potential to produce a repair mortar having the desired properties.

\section{Research Objectives}

The applicability of MWNT reinforced cementitious composites in concrete repair works has been investigated in the present study. A high performance cementitious mortar intended for use in concrete repair should meet several performance criteria. High strength and good bonding with the existing concrete substrate are two important characteristics of a repair material. Setting times are important for fresh cement mortar to be used as repair material. The mortar should not suffer from bleeding since bleeding may adversely affect the durability of repair material. The bond between the repair material and the concrete base often presents a weak link in the repaired structure. This can be evaluated through slant shear test. Since no data is available on the properties of MWNT reinforced cement mortar as concrete repair material, the following tasks were carried out in the current research:

(i) Effect of MWNT addition on setting time was investigated.

(ii) Effect of MWNT addition on bleeding was investigated.

(iii) Bond strength between the repair materials (MWNTcement composite, normal cement mortar, and 
TABLE 1: Properties of used treated MWNT.

\begin{tabular}{|c|c|c|c|c|c|c|c|}
\hline & $\begin{array}{c}\text { OD } \\
\text { (outside } \\
\text { diameter) }\end{array}$ & Length & Purity & Ash & $\begin{array}{c}\text { SSA } \\
\text { (Specific Surface Area) }\end{array}$ & $\begin{array}{l}\text { EC (Electrical } \\
\text { Conductivity) }\end{array}$ & $\begin{array}{l}\mathrm{COOH} \text { content } \\
(\mathrm{wt} \%)\end{array}$ \\
\hline MWNT & $10-20 \mathrm{~nm}$ & $10-30 \mu \mathrm{m}$ & $>95 \mathrm{wt} \%$ & $<1.5 \mathrm{wt} \%$ & $>233 \mathrm{~m}^{2} / \mathrm{g}$ & $>10^{-2} \mathrm{~s} / \mathrm{cm}$ & 2.00 \\
\hline
\end{tabular}

TABLE 2: Proportion of different components used in the initial phase of the study and corresponding strengths of the control and composite samples.

\begin{tabular}{|c|c|c|c|c|c|c|c|c|c|c|}
\hline \multirow[b]{2}{*}{ Sample ID } & \multirow{2}{*}{$\begin{array}{l}\text { MWNT proportion } \\
\text { in terms of cement wt }\end{array}$} & \multirow{2}{*}{$\begin{array}{l}\text { Plasticizer proportion } \\
\text { in terms of cement wt }\end{array}$} & \multirow{2}{*}{$\begin{array}{l}\text { Plasticizer proportion } \\
\text { in terms of MWNT wt }\end{array}$} & \multicolumn{4}{|c|}{ Compressive strength $(\mathrm{MPa})$} & \multicolumn{3}{|c|}{ Flexural strength $(\mathrm{MPa})$} \\
\hline & & & & $\begin{array}{c}3 \\
\text { days }\end{array}$ & $\begin{array}{c}7 \\
\text { days }\end{array}$ & $\begin{array}{c}28 \\
\text { days }\end{array}$ & $\begin{array}{l}100 \\
\text { days }\end{array}$ & 3 days & 7 days & $\begin{array}{c}28 \\
\text { days }\end{array}$ \\
\hline $\mathrm{CS}$ & - & - & - & 23.7 & 27.7 & 33.3 & 37 & 2.86 & 3.3 & 4.67 \\
\hline $\mathrm{CS}+P$ & - & 0.008 & - & 26.1 & 28.6 & 32.8 & 38.6 & - & - & - \\
\hline $0.05 \%+P$ & 0.0005 & 0.008 & 16 & 27.8 & 30.8 & 36 & 40.2 & 3.1 & 3.55 & 4.93 \\
\hline $0.10 \%+P$ & 0.0010 & 0.008 & 8.0 & 29.8 & 33.5 & 38.3 & 42.1 & 3.54 & 4.11 & 5.58 \\
\hline $0.20 \%+P$ & 0.0020 & 0.008 & 4.0 & 28.9 & 33.9 & 37.8 & 42.9 & 3.59 & 3.89 & 5.45 \\
\hline $0.30 \%+P$ & 0.0030 & 0.008 & 2.7 & 28.4 & 35.3 & 38.5 & 42.6 & 3.46 & 3.95 & 5.42 \\
\hline $0.50 \%+P$ & 0.0050 & 0.008 & 1.6 & 26.1 & 29.2 & 33 & 35.7 & - & - & - \\
\hline
\end{tabular}

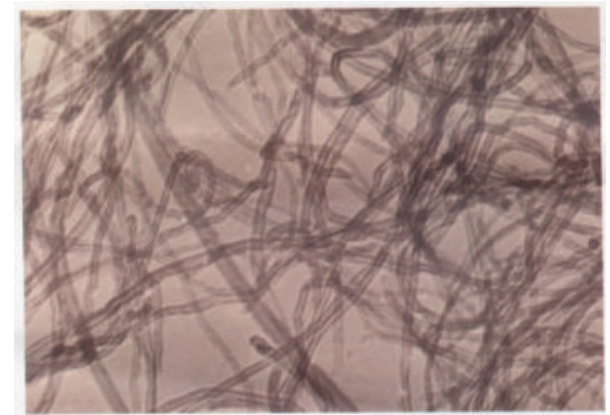

FIGURE 1: TEM image of used treated MWNT with OD of 10-20 nm.

epoxy resin) and concrete substrate was investigated through slant shear tests.

\section{Materials Used}

Ordinary Type II Portland cement was used as cementitious material in this study. Special graded sand according to ASTM C109 [24] was utilized as fine aggregates. A commercially available surface treated MWNT was obtained from the manufacturer (Cheap Tubes Inc.) in powder form having outside diameter (OD) of $10-20 \mathrm{~nm}$. Surface treatment of MWNT was done using a mixture of nitric and sulfuric acids to develop hydroxyl or carboxyl end groups on outer surface of nanotubes. This size of nanotube was selected based on results of the previous study by the authors since this size of surface treated MWNT resulted in relative higher strength [20]. Seven different sizes (outside diameters) of MWNT were used. It was found that, for a given mix proportion, smaller size MWNT reinforcement produced relatively higher compressive strength. Figure 1 shows the Transmission Electron Microscope (TEM) image of the MWNT supplied by the manufacturer. Properties of MWNT are provided in Table 1 which was also supplied by the manufacturer (Cheap Tubes Inc.). Polycarboxylate based super plasticizer ADVA Cast 575 (produced by W. R. Grace \& Co.) was used as plasticizer in the experiments to improve the workability of the mix and also as a surfactant for the MWNT. Texas Department of Transportation (TXDOT) utilizes Pro Poxy 300 for quick repair of cracks in bridges. For slant shear test of specimens jointed by epoxy, Pro Poxy 300 Fast was used.

\section{Experimental Investigation}

Initially, a comprehensive parametric study was conducted in order to obtain a suitable mixing technique for dispersing nanotubes within cement matrix and a tentative optimum mix proportion for producing MWNT reinforced cement composites. Composite samples with different dosages of treated multiwalled carbon nanotubes (MWNTs) and control samples without MWNT were prepared and tested. Samples were made using different mix proportions having different $\mathrm{w} / \mathrm{c}$ (water to cement) ratios and plasticizer proportions. Table 2 shows proportion of different components used in the initial phase of study. The dosage rate of MWNT was also varied to select an optimum concentration. A suitable technique using ultrasonication was employed in dispersing MWNT within the cement matrix [17, 25]. In a typical mixing process, the required amount of plasticizer was first mixed with water and sonicated for few minutes. MWNT was then added in sequence and sonicated in plasticizer mixed water for 5 minutes for each application. After the last addition of MWNT, the whole mixture was sonicated for another $15 \mathrm{~min}$ utes. The amount of MWNT for each sequence was selected in such a way that total sonication time remained constant at 40 minutes. Once sonication was completed, cement, sand, and water (with dispersed nanotubes) were mixed in a mixer with flat beater for about 6 minutes as per ASTM C109 [24] 
requirements. Through SEM images (Figure 2), it has been observed that such sonication can ensure uniform dispersion of nanotubes within cement matrix. The behavior of MWNT reinforced composites in compression and flexure was then evaluated and statistical analysis was carried out. It was found that MWNT reinforced composites performed better both in compression and in flexure. From the initial study, it was observed that composites reinforced with MWNT having OD smaller than $20 \mathrm{~nm}$ yielded relatively higher strength as compared to composites with larger MWNT [20]. It is well established that properties of MWNT reinforced composites primarily depend on proper distribution of nanotubes. Usually, higher water content is required to produce MWNT-cement composites for relative stable dispersion of nanotubes [22, 26]. However, higher water content often produces weaker composites due to its negative effect on cementitious materials. It has been observed that utilization of plasticizer as surfactant makes the dispersion of MWNT into aqueous solution more stable and eventually produces stronger composites [27, 28]. Polycarboxylate based super plasticizer was used as surfactant in this study to make the MWNT more soluble than that of pristine nanotubes. The tentative optimum proportion of plasticizer to be used as surfactant was found as 0.008 in terms of weight of cement [22]. This proportion of plasticizer produced the maximum strength both in compression and in flexure. It was also observed that use of plasticizer increased the flow values of the mix which can be used as an indirect measure of dispersion quality of nanotubes in cement matrix [29]. In the absence of plasticizer, higher water content was required to achieve comparable flow values. It was found that the tentative optimum dosage rate of MWNT in terms of weight of cement ranged between $0.1 \%$ and $0.3 \%$ with lower concentration of MWNT performed better in flexure. Figures 3 and 4 show the compressive and flexural strengths of controls samples and composite samples with different dosage rates of MWNT at different ages, respectively. In each case, twelve samples were prepared and the average strength of twelve samples and corresponding error bands are presented in Figures 3 and 4 . It was evident from the initial study that MWNT reinforcement within cement produced composites with significantly higher strengths. MWNT-cement composites exhibited around 26\%,21\%, 15\%, and 14\% higher compressive strength at 3, 7, 28, and 100 days, respectively, as compared to control samples without plasticizer for $0.10 \%$ addition. The increment in flexural strength was observed to be about $24 \%, 25 \%$, and $20 \%$ at 3,7 , and 28 days, respectively, for similar amount of MWNT addition. It was evident that composites with nanotubes achieved relatively higher 7-day compressive strengths than 28-day strength, as compared to control samples. The reason behind such behavior of nanotube reinforced cement composites is the presence of nanotubes that affects the morphology of cement hydration products. MWNT influences both the initial $\mathrm{C}_{3} \mathrm{~A}$ and the $\mathrm{C}_{3} \mathrm{~S}$ hydration products by accelerating the rate of hydration process particularly at early stages since they act as a matrix for the development of C-S-H and $\mathrm{Ca}(\mathrm{OH})_{2}[1,22]$. It was also observed that composites with higher proportion

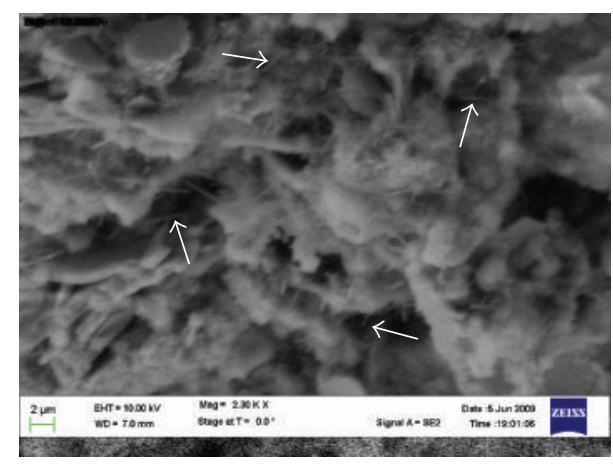

FIGURE 2: SEM image of crushed mortar sample (MWNTs are fairly uniformly distributed as shown by arrows).

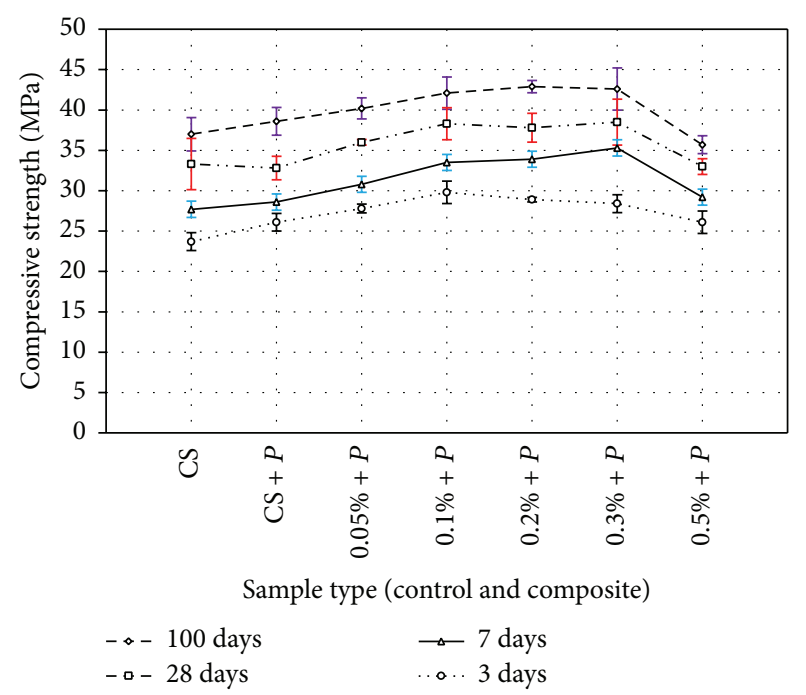

FIGURE 3: Compressive strengths of control and composite samples with different dosage rate of MWNT at different ages.

of MWNT (usually higher than $0.3 \%$ weight of cement) exhibited lower strength values. Higher amount of MWNT resulted in inadequate dispersion due to agglomeration which eventually produced less workable and unstable mixes. It was found that attainment of homogenous distribution using higher amount of nanotubes was extremely difficult even with sonication process. Water also got entrapped between clumped nanotubes and, consequently, hindered the hydration process. Finally, the applicability of MWNT reinforced cement composites as concrete repair material was evaluated through setting time, bleeding, and slant shear tests since these parameters are important to assess the quality of a cementitious repair material. MWNT dosage rates of $0.1 \%$ and $0.3 \%$ were utilized for producing composites to be used as repair material.

\section{Setting Time of Composites}

The time of setting represents the onset of the solidification phase at which fresh mortar can no longer be properly handled or injected. This test is significant for evaluating the effect of MWNT addition on setting time of cementitious 


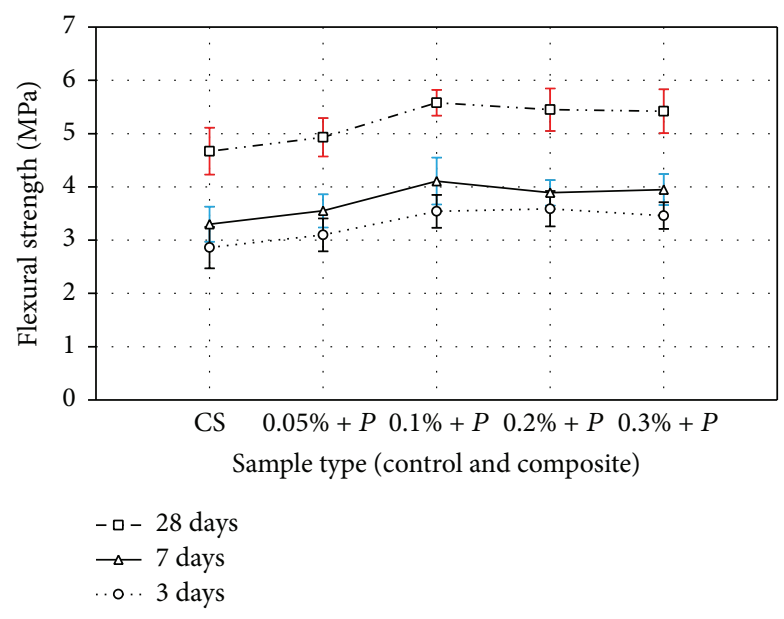

FIGURE 4: Flexural strengths of control and composite samples with different dosage rate of MWNT at different ages.

mortar. The setting time is particularly important for repair purposes regarding practical use of repair mortar in field. The setting times were determined using the Vicat apparatus described in ASTM C807 [30]. The ASTM C807 test procedure is for determination of the time of setting of hydraulic cement mortar. The modified setting time test utilizes thicker steel needle of $2.0 \mathrm{~mm}$ instead of $1.0 \mathrm{~mm}$ needle. The $1.0 \mathrm{~mm}$ needle is used for determination of setting time of cement paste.

5.1. Sample Preparation and Testing. Control and composite samples reinforced with $0.1,0.2$, and $0.3 \%$ MWNT were prepared and tested for time of setting. Samples were produced using $\mathrm{w} / \mathrm{c}$ ratio of 0.50 and 0.60 . Control samples with plasticizer addition were also made for comparison. Two different plasticizer proportions of 0.005 and 0.008 as surfactant were used to prepare composites. Samples were prepared using the rotary mixture with flat beater. After preparation, the samples were kept in moisture room for 30 minutes without being disturbed. For testing, samples were then placed on Vicat apparatus and the needle was set in contact with the surface of mortar samples. The needle was then released to penetrate and allowed to set for 30 seconds. The reading of penetration was measured and recorded. The penetration readings were then determined at every 30 minutes till the needle failed to touch the bottom of the mold. After that the reading was taken at 10-minute intervals until a reading of $10 \mathrm{~mm}$ or less was obtained. From all recorded penetration readings, the time when penetration was $10 \mathrm{~mm}$ was determined through interpolation. Each penetration of needle was done at a distance of $10 \mathrm{~mm}$ from any previous penetration and from the inside edge of the mold. The difference in time between the mixing of mortar and a penetration of $10 \mathrm{~mm}$ was the setting time of cementitious mortar.

5.2. Results and Discussion on Setting Time. It was observed that composite samples with nanotubes settled significantly early as compared to control samples for the same mix

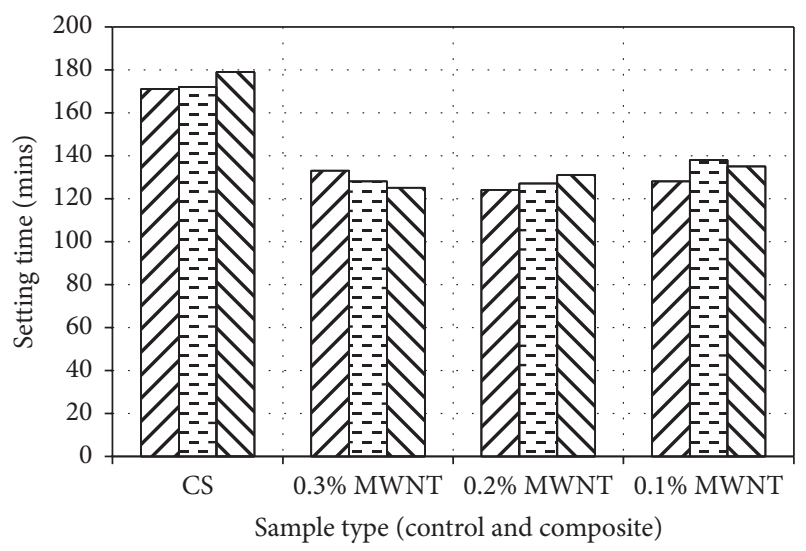

FIGURE 5: Time of setting of control samples without plasticizer and composites with different dosage rate of MWNT having w/c ratio of 0.50 .

proportions. Control samples with w/c ratio of 0.50 had time of setting of around 175 minutes. Composites reinforced with $0.1 \%$ to $0.3 \%$ MWNT showed setting time ranging between 125 and 135 minutes. Control samples with plasticizer proportion of 0.008 had setting time of about 340 minutes. Setting times for $0.3 \%$ and $0.1 \%$ MWNT reinforced composites with plasticizer proportion of 0.008 as surfactant were observed as 245 and 260 minutes, respectively. Hence, about $25 \%$ less time was required by the MWNT composite to set than that of control samples for mixes with plasticizer proportion of 0.008 . Similar pattern was also observed for other mix proportions of control and composite samples. In case of mixes with w/c ratio of 0.60 , MWNT composites required about $14 \%$ less time for setting as compared to control samples. It is, therefore, evident that addition of nanotubes decreases the initial setting time of cement mortar since presence of nanotubes accelerates the rate of hydration of initial $\mathrm{C}_{3} \mathrm{~A}$ by acting as nucleating agent. And, the stiffening and setting characteristics of cement paste primarily depend on hydration of aluminates. It was also found that the variation in setting time with the change in concentration of MWNT between $0.1 \%$ and $0.3 \%$ was little. Hence, it appears that amount of nanotubes within this range has similar effect on cement hydration which is also evident from strength results. Figures 5-7 show the comparison between times of setting of control and composite samples having different mix proportions. Each bar in the graphs represents one sample for the respective mix proportion; that is, the three bars under CS in Figure 5 are representing setting time of three control samples having w/c ratio of 0.50 . In Figure $6, P$ means plasticizer and different percent values represent amount of MWNT; that is, $0.3 \%+P-0.005$ means composite samples with $0.3 \%$ MWNT and plasticizer proportion of 0.005 . All samples with plasticizer were made using $\mathrm{w} / \mathrm{c}$ ratio of 0.50 .

\section{Bleeding of Composites}

Bleeding is the appearance of free water on the surface of the unset mortar, as the relatively heavy solid particles settle 


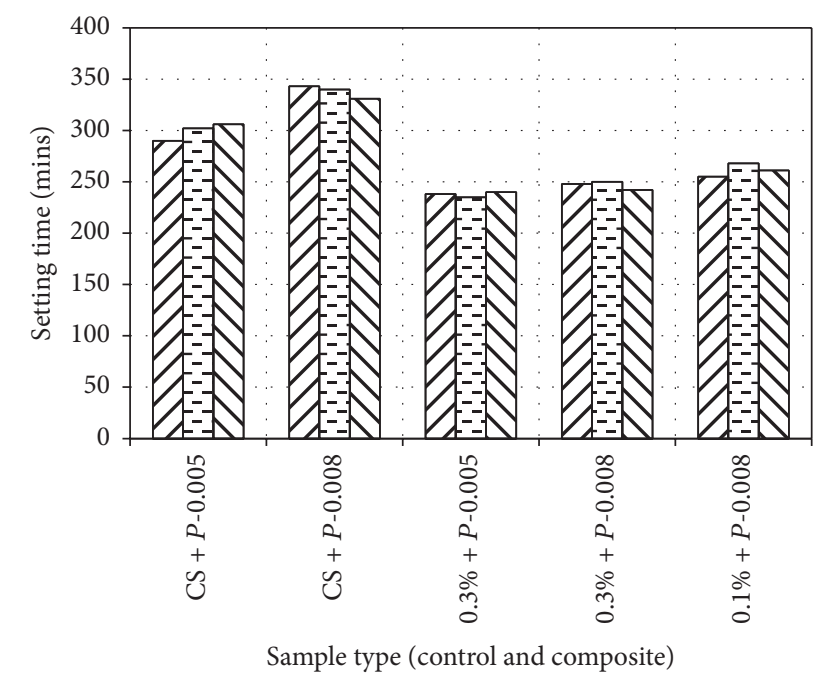

FIgURE 6: Time of setting of control samples and composites with plasticizer (w/c ratio: 0.50$)$.

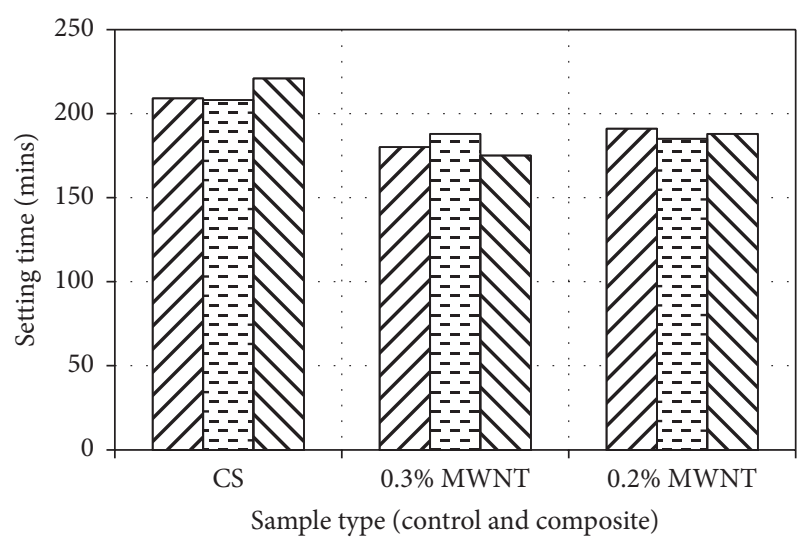

FIGURE 7: Time of setting of control samples without plasticizer and composites with different dosage rate of MWNT having w/c ratio of 0.60 .

because of gravity, and represents the quality of the mortar mix. Bleeding of the freshly mixed mortar was measured following the procedure given in ASTM C940 [31]. Excessive bleeding may leave several uncontrolled open channels within the mortar mass and eventually results in porous and weak samples. It also adversely affects the durability of the sample. Therefore, composite samples should be free from bleeding to be used as an effective repair material.

6.1. Sample Preparation and Testing. $800 \mathrm{~mL}$ of freshly mixed cement mortar was produced for each test of bleeding. Both control and composite samples were made and tested for bleeding. Composite samples were prepared with $0.1 \%$ and $0.3 \%$ dosage rate of MWNT having different mix proportions for comparison. After completion of mixing, the temperature of the mix was measured and recorded. The mix was then poured into a $1000 \mathrm{~mL}$ glass graduated cylinder and covered. The difference between the upper surface of mortar and bleed water was then recorded if any difference was observed. The process was continued at 15-minute intervals for the first 60 minutes and then at 1-hour intervals. The height of bleed water was then expressed as a percent of the original height of the mortar. This height was referred to as the percent final bleed.

6.2. Results and Discussion on Bleeding. Table 3 provides the bleeding results and corresponding temperatures of both control and composites samples. It was observed that none of the samples, either control or composite, exhibited bleeding. Therefore, it is evident that addition of nanotubes does not affect the stability of the cementitious mix. The temperature of MWNT reinforced cement composites has been found significantly higher than that of control samples. Presence of MWNT accelerates the hydration process which eventually increases the temperature of the mix.

\section{Bonding Strength of Composites and Repair Materials}

The bond strength between the repair material and concrete substrate plays an important role in the efficiency of repair material used in concrete structures. Slant shear tests are typically employed to measure this bond strength since it is considered as the most effective method of compressive shear testing [32-34]. The bond between the repair material and the old concrete usually presents a weak link in the repaired structure. The MWNT reinforced composites should exhibit good bonding strength with existing concrete substrate to be utilized as repair material. Slant shear test was conducted to evaluate the bonding strength. Slant shear strengths of control and composite mortar were measured following the procedure given in ASTM C882/C882M-05 [35] and DMS 4655 [36]. Epoxy resins are widely used to repair cracks in concrete structures. TXDOT utilizes Pro Poxy 300 for quick repair of cracks in bridges. Slant shear test of specimens jointed by Pro Poxy 300 Fast was therefore carried out for comparison.

7.1. Sample Preparation and Testing. The cylinders with $75 \mathrm{~mm}$-by-150 $\mathrm{mm}$ dimensions were produced according to ASTM C882/C882M and DMS 4655 procedures. The compressive strength of cylinders should be higher than the slant shear strength of the repair material in order to suppress the failure of precast cylinders. After suitable curing, the slant test cylindrical specimens were saw cut into halves with a diagonal bonding area at an angle of $30^{\circ}$ from the vertical, as illustrated in Figure 8. Fresh normal cement and CNTcement mortar layers with a thickness of $3 \mathrm{~mm}$ were then placed on the diagonal bonding area between the two saw cut halves. Also epoxy resin was used on the bonding area of other specimens for comparison purpose. The thickness of epoxy resin was used as $0.5 \mathrm{~mm}$ according to ASTM standard. The slant shear strengths of specimens repaired by CNTcement mortar and epoxy resin were obtained by conducting a series of compression tests.

The 28-day compressive strength of concrete cylindrical specimen must be between 34.5 and $41.4 \mathrm{MPa}$ to be used for slant shear testing as per DMS 4655. Concrete cylinders were 
TABLE 3: Bleeding test result of control and composite samples.

\begin{tabular}{lccccc}
\hline Type of sample & $\begin{array}{c}\text { Amount of } \\
\text { MWNT (\%) }\end{array}$ & $\begin{array}{c}\text { w/c } \\
\text { ratio }\end{array}$ & $\begin{array}{c}\text { Amount of plasticizer } \\
\text { (as part of cement by wt.) }\end{array}$ & Bleeding $(\%)$ & Temp $\left({ }^{\circ} \mathrm{C}\right)$ \\
\hline Control & NA & 0.50 & NA & NA & None \\
Composite & 0.3 & 0.50 & NA & None & 27.4 \\
Composite & 0.3 & 0.60 & 0.008 & None & 31 \\
Composite & 0.3 & 0.50 & NA & None & 28.8 \\
Composite & 0.1 & 0.50 & 0.008 & None & 26.7 \\
Composite & 0.1 & 0.50 & 27.2 \\
\hline
\end{tabular}
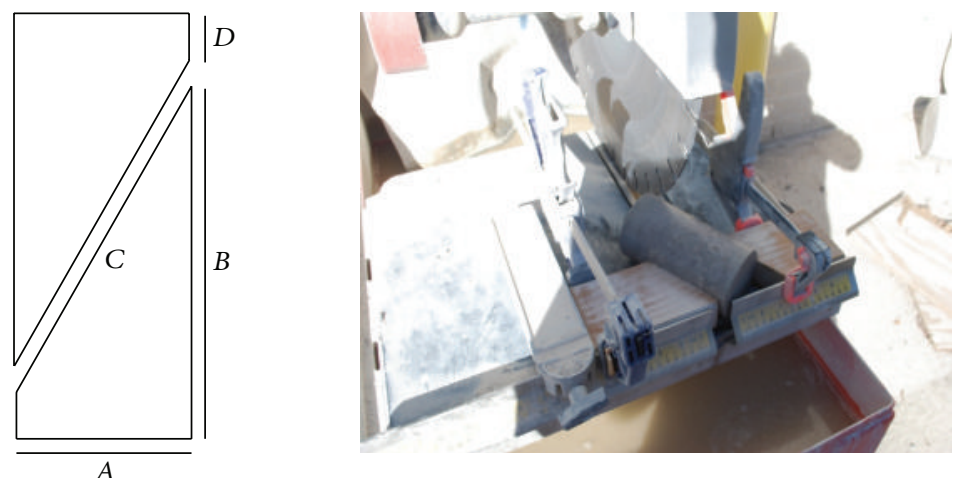
(A) Diameter $75 \pm 2 \mathrm{~mm}$
(B) Height $140 \pm 2 \mathrm{~mm}$
(C) Slant height $150 \pm 2 \mathrm{~mm}$
(D) Base height $10 \pm 2 \mathrm{~mm}$

FIGURE 8: Dimensions of cylindrical specimens used for the standard slant shear test of ASTM C882/C882M and cutting arrangement.

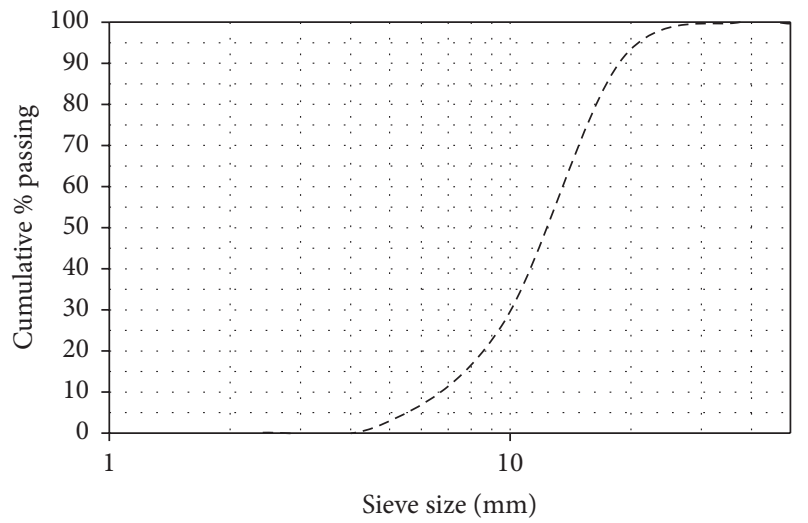

FIGURE 9: Gradation of coarse aggregates.

made following the ACI mix design procedures. The $\mathrm{w} / \mathrm{c}$ ratio of 0.44 was used for the concrete mix. The gradation of coarse aggregates is shown in Figure 9. The bulk specific gravity of coarse aggregate was obtained as 2.64. The fineness modulus (FM) of fine aggregate was calculated as 2.68. The FM was determined using the formula as shown in the following equation. The standard sieves for FM calculation of fine aggregates are $4.75 \mathrm{~mm}, 2.36 \mathrm{~mm}, 1.18 \mathrm{~mm}, 600 \mu \mathrm{m}, 300 \mu \mathrm{m}$, and $150 \mu \mathrm{m}$. The bulk specific gravity of coarse aggregate and $\mathrm{FM}$ of fine aggregate were required to proportion the concrete mix as per ACI mix design method for the design strength. Consider

$$
\mathrm{FM}=\frac{\sum \text { (cumulative percent retained on standard sieves) }}{100} .
$$

Slant shear tests were carried out at 3, 7, and 28 days. Composites samples were made with $0.1 \%$ and $0.3 \%$ dosage rate of MWNT with plasticizer proportion of 0.008 as surfactant. The $\mathrm{w} / \mathrm{c}$ ratio was kept at 0.50 . Control samples were made with $\mathrm{w} / \mathrm{c}$ ratio of 0.50 . In each case, a total of 3 cylindrical specimens were jointed together and tested at designated days. Figure 10 shows specimens prepared through bonding by MWNT reinforced composite and epoxy.

7.2. Results and Discussion on Slant Shear. Two sets (each containing 3 samples) of cylindrical specimens were tested for compressive strength at 28 days. Average compressive strengths of the two sets were 41.3 and $39.7 \mathrm{MPa}$, respectively, which fall within the limit given by DMS 4655 . The slant shear test results are shown in Figure 11. It was found that slant shear strength of epoxy at 3 and 7 days was much greater (almost double) than that of both control and composite mortar. This type of behavior was expected as Pro Poxy 300 Fast is a quick hardening epoxy resin and gains strength very rapidly. The slant shear strengths of $0.1 \%$ MWNT reinforced composites were about $20 \%$ and $23 \%$ higher than that of normal cement mortar at 3 and 7 days, 


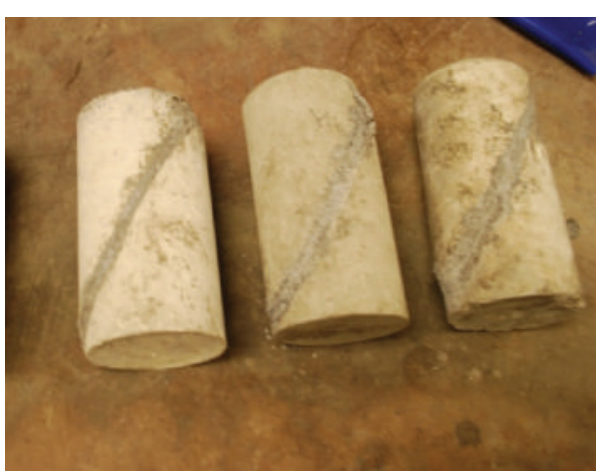

(a)

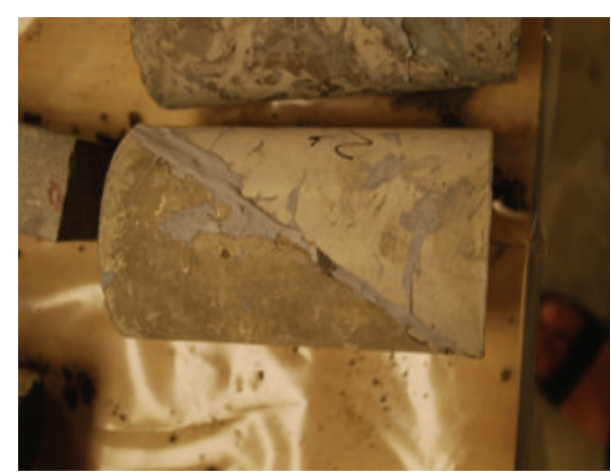

(b)

FIgURE 10: (a) Cylindrical specimens bonded together by MWNT composite. (b) Cylindrical specimens bonded by epoxy.

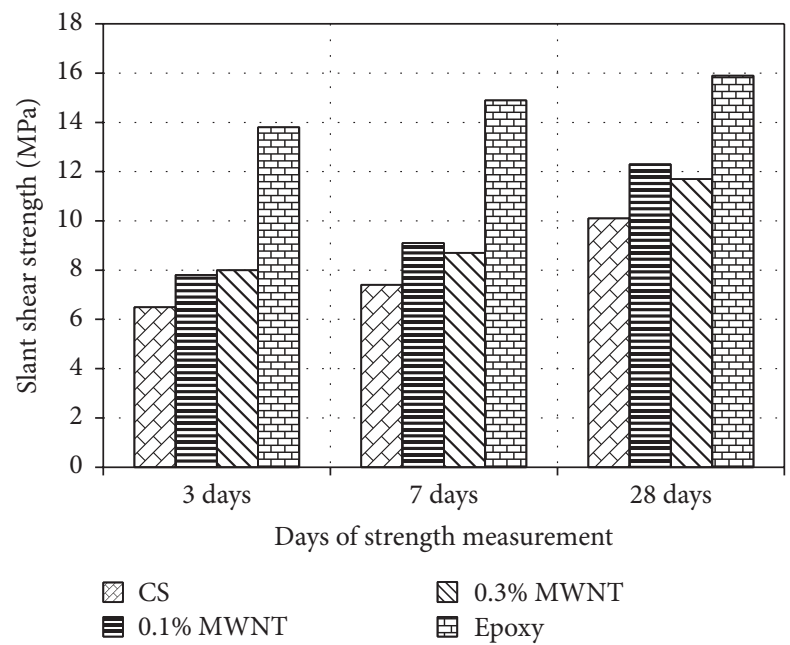

FIGURE 11: Slant shear strength of different repair material at different ages.

respectively. At 28 days, the $0.1 \%$ MWNT composites had about 22\% higher slant shear strength than control mortar. Such increment in slant shear strength of MWNT composites was due to the enhanced strength properties of MWNT reinforced cementitious composites. Control mortar showed about $53 \%$ and $50 \%$ less slant shear strengths as compared to Pro Poxy 300 at 3 and 7 days, respectively, whereas the 3- and 7-day slant shear strengths of $0.1 \%$ MWNT-cement mortar were about $44 \%$ and $40 \%$ less than that of Pro Poxy 300 , respectively. However, the 28-day slant shear strengths of cylindrical specimens repaired using MWNT reinforced mortar were relatively close to that repaired using epoxy as compared to 3- and 7-day strength. It is evident from the obtained results that cementitious mortar reinforced with surface treated MWNT showed enhanced performance in slant shear strength compared to control mortar at all ages considered in this study. On the other hand, as compared to epoxy resin, MWNT reinforced composites exhibited relatively lesser bonding strength particularly at early ages. However, cement mortar with $0.1 \%$ MWNT content achieved almost $80 \%$ of the slant shear strength of Pro Poxy at 28 days. Hence, it can be said that MWNT reinforcement within cement composites showed good potential to be used as repair grout. Nevertheless, further research is needed to improve the bonding performance of such nanotubes reinforced mortar. Figure 12 shows the specimens after slant shear test for both MWNT reinforced mortar and epoxy bonded specimens. In both cases, failure occurred at the bonding plane.

\section{Conclusion}

MWNT reinforced cementitious composite has already proven its enhanced mechanical properties in terms of both compressive and flexural strength. However, past researches have shown variable increase in strengths of nanotube reinforced cementitious composites ranging from none to more than $80 \%$ for different mixing process and concentration of CNT. Hence, it is imperative to develop a suitable mixing technique and recommend a tentative optimum mix ratio for producing nanotube reinforced cement composites. The mixing procedure and mix proportions developed and used in this study have been found to be satisfactory in producing stable MWNT reinforced composites with enhanced mechanical properties. The composites thus produced exhibited about $15 \%$ and $20 \%$ higher compressive and flexural strength than those of plain cement mortar, respectively. The suitability of the produced MWNT reinforced composites as concrete repair material was then investigated through setting time, bleeding, and slant shear tests. The setting time results show that nanotubes reinforced cement mortar hardened quite more rapidly than normal cement mortar. It required almost $25 \%$ less time to set as compared to plain cement mortar. Rapid setting is very important for a material to be used as repair material. It was also observed that composites with nanotubes showed no sign of bleeding. Bleeding can adversely affect the overall strength and durability of a repair material. Slant shear strengths of nanotubes reinforced composites were also found to be higher than that of control plain mortar samples at all ages of 3, 7, and 28 days. The $0.1 \%$ dosage rate performed a little better as compared to $0.3 \%$ dosage rate in slant shear tests. As compared to epoxy, MWNT reinforced composites exhibited lower slant shear strengths particularly at early ages of 3 and 7 days. 


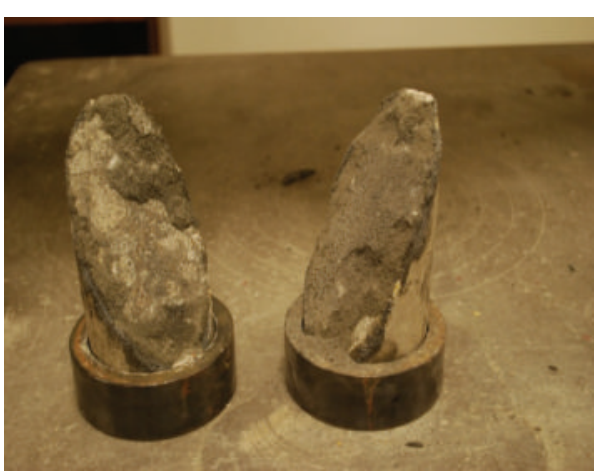

(a)

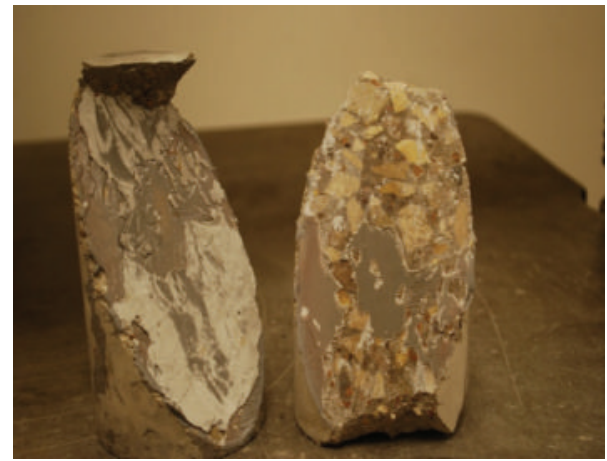

(b)

FIGURE 12: (a) Specimens (bonded by MWNT reinforced composite) after testing. (b) Specimens (bonded by epoxy) after testing.

The reason behind such behavior was the extremely rapid hardening characteristics of Pro Poxy 300 Fast. The 28-day slant shear strengths of composites achieved relatively higher value which was almost equal to 80 percent of epoxy resin strength. Therefore, it can be said that initial test results on applicability of MWNT reinforced cement composites as repair material demonstrate good potential. However, this type of investigation is presently at budding phase. As a result, more research is required in this field. Several issues like flowability of MWNT-cement mortar, pullout strength, and so forth need to be investigated before recommending practical application of such nanotube reinforced repair material. In addition, any health concern regarding practical use of nanotubes should also be kept in mind. In this study, experiments were conducted following appropriate safety precautions under controlled environment of laboratory. Chemical-resistant gloves, safety goggles, respirators, and protective clothing were used. Comprehensive investigation regarding potential health hazards of using nanotubes in field scale must be conducted simultaneously.

\section{Conflict of Interests}

The authors declare that there is no conflict of interests regarding the publication of this paper.

\section{References}

[1] J. Makar, J. Margeson, and J. Luh, "Carbon nanotube/cement composites-early results and potential application," in Proceedings of the 3rd International Conference on Construction Materials: Performance, Innovations and Structural Implications, pp. 1-10, Vancouver, Canada, August 2005.

[2] L. X. Zheng, M. J. O'Connell, S. K. Doorn et al., "Ultralong single-wall carbon nanotubes," Nature Materials, vol. 3, no. 10, pp. 673-676, 2004.

[3] M.-F. Yu, B. S. Files, S. Arepalli, and R. S. Ruoff, "Tensile loading of ropes of single wall carbon nanotubes and their mechanical properties," Physical Review Letters, vol. 84, no. 24, pp. 5552$5555,2000$.

[4] J.-P. Salvetat, J.-M. Bonard, N. H. Thomson et al., "Mechanical properties of carbon nanotubes," Applied Physics A, vol. 69, no. 3, pp. 255-260, 1999.
[5] D. A. Walters, L. M. Ericson, M. J. Casavant et al., "Elastic strain of freely suspended single-wall carbon nanotube ropes," Applied Physics Letters, vol. 74, no. 25, pp. 3803-3805, 1999.

[6] P.-W. Chen and D. D. L. Chung, "Concrete reinforced with up to 0.2 vol\% of short carbon fibres," Composites, vol. 24, no. 1, pp. $33-52,1993$.

[7] H. Li, H.-G. Xiao, J. Yuan, and J. Ou, "Microstructure of cement mortar with nano-particles," Composites Part B: Engineering, vol. 35, no. 2, pp. 185-189, 2004.

[8] G. Y. Li, P. M. Wang, and X. Zhao, "Mechanical behavior and microstructure of cement composites incorporating surfacetreated multi-walled carbon nanotubes," Carbon, vol. 43, no. 6 , pp. 1239-1245, 2005.

[9] C. Balázsi, F. Wéber, Z. Kövér et al., "Application of carbon nanotubes to silicon nitride matrix reinforcements," Current Applied Physics, vol. 6, no. 2, pp. 124-130, 2006.

[10] F. Lupo, R. Kamalakaran, C. Scheu, N. Grobert, and M. Rühle, "Microstructural investigations on zirconium oxide-carbon nanotube composites synthesized by hydrothermal crystallization," Carbon, vol. 42, no. 10, pp. 1995-1999, 2004.

[11] D. Tasis, S. Pispas, C. Galiotis, and N. Bouropoulos, "Growth of calcium carbonate on non-covalently modified carbon nanotubes," Materials Letters, vol. 61, no. 28, pp. 5044-5046, 2007.

[12] M. L. Terranova, S. Orlanducci, A. Fiori et al., "Controlled evolution of carbon nanotubes coated by nanodiamond: the realization of a new class of hybrid nanomaterials," Chemistry of Materials, vol. 17, no. 12, pp. 3214-3220, 2005.

[13] A. Cwirzen, K. Habermehl-Cwirzen, and V. Penttala, "Surface decoration of carbon nanotubes and mechanical properties of cement/carbon nanotube composites," Advances in Cement Research, vol. 20, no. 2, pp. 65-73, 2008.

[14] J. V. Agullo, V. C. Ligero, D. P. Rico et al., "Mortar and concrete reinforced with nanomaterials," Nanotechnology in Construction, vol. 3, pp. 383-388, 2009.

[15] J. M. Makar and G. W. Chan, "Growth of cement hydration products on single-walled carbon nanotubes," Journal of the American Ceramic Society, vol. 92, no. 6, pp. 1303-1310, 2009.

[16] M. S. Konsta-Gdoutos, Z. S. Metaxa, and S. P. Shah, "Highly dispersed carbon nanotube reinforced cement based materials," Cement and Concrete Research, vol. 40, no. 7, pp. 1052-1059, 2010.

[17] T. Manzur and N. Yazdani, "Strength enhancement of cement mortar with carbon nanotubes: early results and potential," 
Journal of the Transportation Research Board, no. 2142, pp. 102108, 2010.

[18] A. M. Hunashyal, S. V. Tippa, S. S. Quadri, and N. R. Banapurmath, "Experimental investigation on effect of carbon nanotubes and carbon fibres on the behavior of plain cement mortar composite round bars under direct tension," ISRN Nanotechnology, vol. 2011, Article ID 856849, 6 pages, 2011.

[19] B. Han, Z. Yang, X. Shi, and X. Yu, "Transport properties of carbon-nanotube/cement composites," Journal of Materials Engineering and Performance, vol. 22, no. 1, pp. 184-189, 2013.

[20] T. Manzur, N. Yazdani, and M. A. B. Emon, "Effect of carbon nanotube size on compressive strengths of nanotube reinforced cementitious composites," Journal of Materials, vol. 2014, Article ID 960984, 8 pages, 2014.

[21] M. Lelusz, "Carbon nanotubes influence on the compressive strength of cement composites," Technical Transactions, Civil Engineering 1-B/2014, 2014.

[22] T. Manzur and N. Yazdani, "Optimum mix ratio for carbon nanotubes in cement mortar," KSCE Journal of Civil Engineering, vol. 19, no. 5, pp. 1405-1412, 2015.

[23] S. Parveen, S. Rana, and R. Fangueiro, "A review on nanomaterial dispersion, microstructure, and mechanical properties of carbon nanotube and nanofiber reinforced cementitious composites," Journal of Nanomaterials, vol. 2013, Article ID 710175, 19 pages, 2013.

[24] American Society for Standard Testing and Materials (ASTM), Standard Test Method for Compressive Strength of HydraulicCement Mortars, ASTM C109-07, American Society for Standard Testing and Materials, West Conshohocken, Pa, USA, 2008.

[25] T. Manzur, Nano-modified cement composites and its applicability as concrete repair material [Ph.D. thesis], University of Texas at Arlington, Arlington, Tex, USA, 2011.

[26] S. Musso, J.-M. Tulliani, G. Ferro, and A. Tagliaferro, "Influence of carbon nanotubes structure on the mechanical behavior of cement composites," Composites Science and Technology, vol. 69, no. 11-12, pp. 1985-1990, 2009.

[27] C. Gay and F. Sanchez, "Performance of carbon nanofibercement composites with a high-range water reducer," Journal of the Transportation Research Board, vol. 2142, pp. 109-113, 2010.

[28] A. Yazdanbakhsh, Z. Grasley, B. Tyson, and R. K. Abu Al-Rub, "Distribution of carbon nanofibers and nanotubes in cementitious composites," Journal of the Transportation Research Board, vol. 2142, pp. 89-95, 2010.

[29] T. Manzur and N. Yazdani, "Importance of flow values in qualitative evaluation of carbon nanotube reinforced cementitous matrix," Malaysian Journal of Civil Engineering, vol. 25, no. 1, pp. 71-80, 2013.

[30] American Society for Standard Testing and Materials (ASTM), "Standard test method time for of setting of hydraulic cement mortar by modified vicat needle," ASTM C 807-08, West Conshohocken, Pa, USA, 2009.

[31] American Society for Standard Testing and Materials (ASTM), Standard Test Method for Expansion and Bleeding of Freshly Mixed Grouts for Preplaced-Aggregate Concrete in the Laboratory, ASTM C940-98, American Society for Standard Testing and Materials, West Conshohocken, Pa, USA, 2008.

[32] K. N. Bakshs, Evaluation of bond strength between overlay and substrate in concrete repairs [M.S. thesis], School of Architecture and the Built Environment, Royal Institute of Technology (KTH), Stockholm, Sweden, 2010.
[33] R. Abbasnia, M. Khanzadi, and J. Ahmadi, "Mortar mix proportions and free shrinkage effect on bond strength between substrate and repair concrete," in Concrete Repair, Rehabilitation and Retrofitting II, M. G. Alexander, H. Beushausen, and F. Dehn, Eds., Taylor \& Francis Group, London, UK, 2009.

[34] E. N. B. S. Júlio, F. A. B. Branco, and V. D. Silva, "Concreteto-concrete bond strength. Influence of the roughness of the substrate surface," Construction and Building Materials, vol. 18, no. 9, pp. 675-681, 2004.

[35] American Society for Standard Testing and Materials (ASTM), "Standard test method for bond strength of epoxy-resin systems used with concrete by slant shear," ASTM C 882-05, ASTM, West Conshohocken, Pa, USA, 2008.

[36] Texas Department of Transportation (TXDOT), "Concrete repair materials," Departmental Material Specification DMS4655, TXDOT, 2009. 

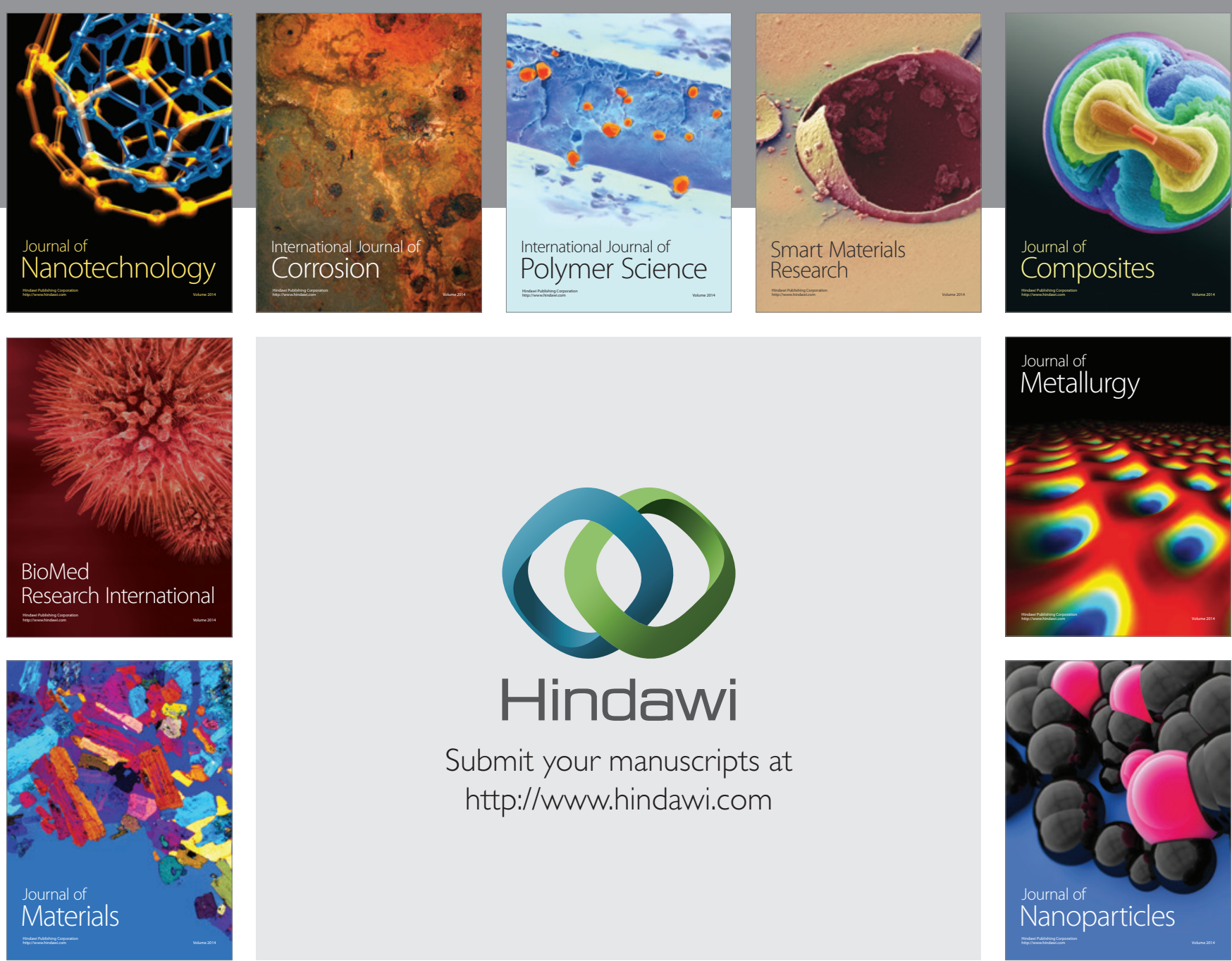

\section{Hindawi}

Submit your manuscripts at

http://www.hindawi.com

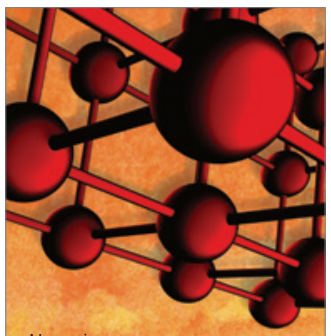

Materials Science and Engineering
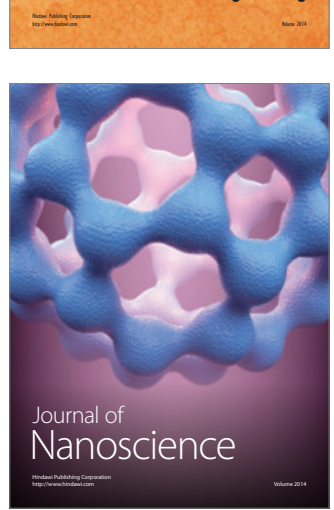
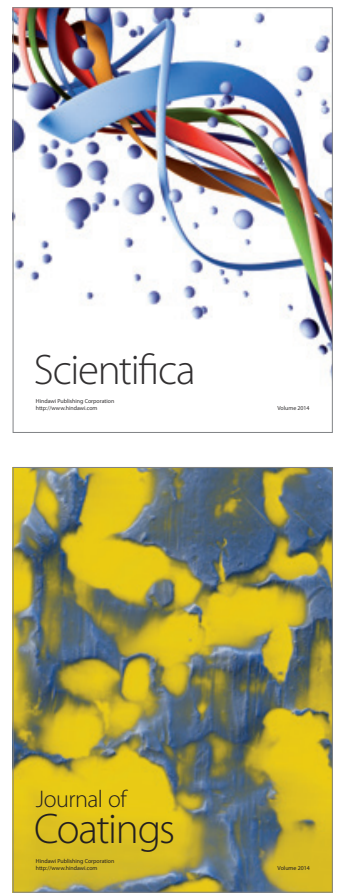
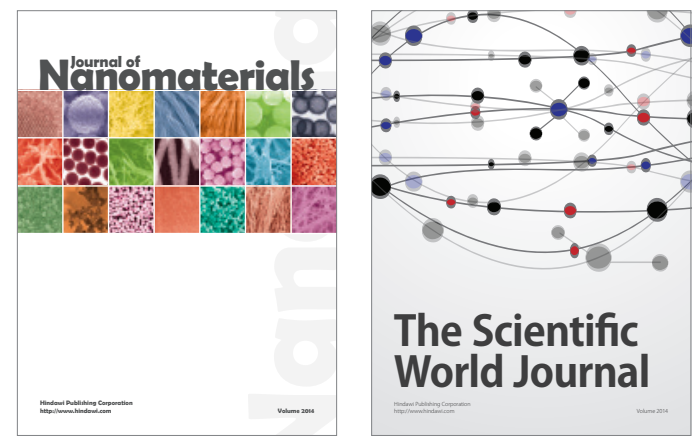

The Scientific World Journal
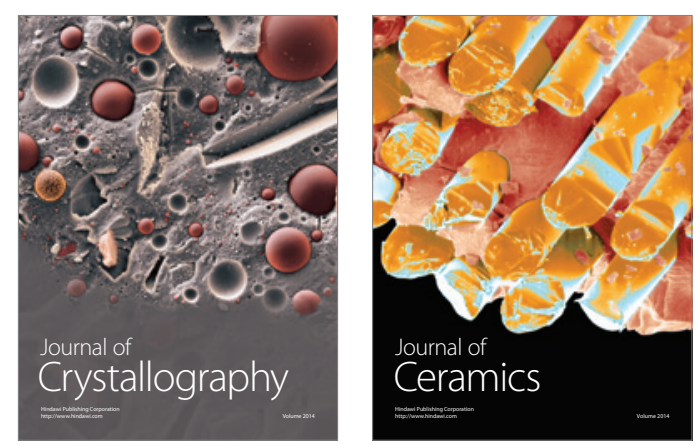
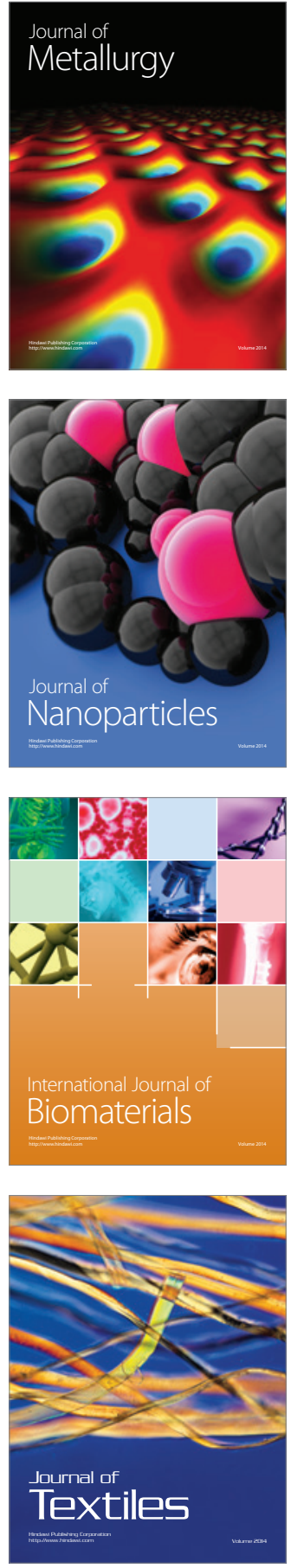